\title{
Esperanza: los afectos y el cuerpo como fundamentos de la vida en Cuando azota el frío (EUNA, 2017), de Álvaro Vega Sánchez
}

Hope: the affections and the body as the foundations of life in Cuando azota el frío [When the cold hits] (EUNA, 2017) by Álvaro Vega Sánchez

\section{Esperança: as afeições e o corpo como as fundações da vida em Cuando azota el frío [Quando o frio atinge] (EUNA, 2017) de Álvaro Vega Sánchez}

Gilbert Ulloa Brenes

Recibido: 03/09/2018

Me parece oportuno señalar que tuve el privilegio de ser uno de los primeros lectores del manuscrito original de este libro, pues su autor, Álvaro Vega, tuvo a bien compartirlo conmigo. Y gracias a esta primicia lectora pude dar forma hace ya algunos años a parte de las ideas que aquí retomaré, cuando en aquel momento remití mis comentarios a Álvaro.

La lectura de aquel original manuscrito y la relectura

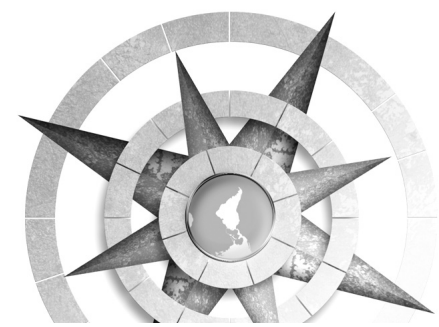

DOI: https://doi.org/10.15359/tdna.34-64.9

Julio-diciembre, 2018137 Vol. $34, \mathrm{~N}^{\circ} 64$ del hoy ya publicado texto, se trató de una grata tarea que emprendí sin desatender la admiración que siento por la claridad de las ideas de Álvaro y, sobre todo, por la fundamental y valiente Esperanza que se transparenta a lo largo de Cuando azota el frío.

Y es que esa Esperanza, en mi criterio, es el pilar ético que percibo en Álvaro como pensador de lo social que es, y era también un elemento transversal que percibí en años atrás cuando tuve el privilegio de ser estudiante en los cursos que Álvaro impartiera en la Maestría en Estudios de Cultura Centroamericana de la Universidad Nacional.

En ese sentido, me resulta difícil separar las ideas medulares que pueden leerse en Cuando azota 
el frío, de las ideas y acciones que se pueden identificar en Álvaro como profesor, amigo y escritor. Por ello, el libro que se reseña aquí, me parece algo más que páginas escritas con intención de "analizar" un "fenómeno" social que se mira con pretendida objetividad: se trata, en mi criterio, de un ensayo que, tal como advierte Álvaro en las primeras páginas cuando se refiere a los fundamentos de algunos movimientos sociales contemporáneos, está también escrito desde afectos humanamente bondadosos.

Por ello la Esperanza en la capacidad de esos movimientos basados en los afectos, en el saber del cuerpo y la apetencia que colectivamente nos mueve para transformar realidades opresoras, es el tono que uno percibe en la pluma de Álvaro. No es mera coincidencia, entonces, la constante intertextualidad que hay con las obras de Erich Fromm, autor que se puede reconocer como uno de los pensadores que más confianza albergaba en la potencial bondad del ser humano para llevar adelante transformaciones sociales desde la esperanza, en tanto esta es un intenso estado de "estar listo para actuar" (Fromm, 1970, p. 23), según la definición ofrecida en La revolución de la esperanza.

Por otra parte, lo corporal y lo emotivo adquieren especial relevancia en
Cuando azota el frío, tal como se ilustra, por ejemplo, en el siguiente pasaje:

más allá de enarbolar razones y argumentos "ideológicos", al estilo predominante en las luchas sociales del siglo XX, la ciudadanía de hoy se manifiesta y moviliza mostrando un nuevo "rostro", una nueva modalidad de lucha social, que otorga especial importancia al factor corporal-emotivo, el cual adquiere un particular significado cultural y sociopolítico; la defensa de los derechos humanos y de la naturaleza -concebidos como inseparables- asumen una dimensión donde se ve implicado, de manera sustantiva, al sujeto humano como corporalidad sensible y diversa (Vega, 2017, p. 124).

Destaco este pasaje en la obra de Álvaro pues, en mi criterio, esa idea es el corazón del análisis que se nos ofrece: la irrupción de nuevas formas de ciudadanía cuya base cohesiva y ética es lo corporal-emotivo matizado desde una novedosa trama simbólica que la reviste de un especial poder cultural y político.

Veo en esta idea un planteamiento además de valioso, valiente. Es decir, de un valor epistémico y ético integral. El tono del ensayo, combinación de análisis social y problematización teleológica, conjuga, en efecto, un muy actualizado vistazo a

138 Esperanza: los afectos y el cuerpo como fundamentos de la vida en Cuando azota el frío (EUNA, 2017), de Álvaro Vega Sánchez Gilbert Ulloa Brenes

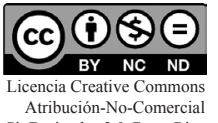


diversos acontecimientos de movilización civil que se han dado en los últimos años, en diversos países (en Costa Rica también contamos hoy con algunos ejemplos de movimientos de este tipo que han impactado y seguramente seguirán repercutiendo de manera más profunda en nuestra inercia social, por ejemplo, la actividad que desarrolló y desarrolla la Coalición Costa Rica), con lo que me gustaría llamar la emergencia de un espacio ético para la participación: el de la comunidad de afectos.

A riesgo de reducir la riqueza del texto a una particularísima idea, veo en la aproximación que efectúa Álvaro a este tema, el bullir de una nueva forma de erótica de la convivencia humana en la que lo individual, lo social y lo corporal se amalgaman en el crisol de los buenos afectos, por ser humanamente bondadosos y estar encauzados con las potencias biofílicas.

Destaco que Cuando azota el frío recupera el potencial de los afectos agregando con ello lo que ya desde Erich Fromm se ha convertido en motivo de un pospuesto debate que vale la pena retomar: que la vida humana debe regirse no por cualquier tipo de emociones o de normas de convivencia, en consonancia con un nocivo relativismo ético (ver al respecto Fromm, 1953, pp. 15-19), sino por aquellas que permiten a los seres humanos ser plenamente libres y capaces de amar, construir y seguir ideales que apunten a la vida, no a la muerte.

Por su fondo, Cuando azota el frío se puede alinear del lado de los presupuestos de autores como Reich, Marcuse o Fromm que destacaron, en su momento, el poder emancipador de las emociones y la corporalidad a contrapelo de la enajenación en la cual la imperante racionalidad instrumental pretendió y pretende enclaustrar al ser humano, ofreciéndole a cambio placebos de pretendida libertad paradójicamente constreñida por los dictámenes del mercado y el capital.

En mi criterio, esa línea que corre a lo largo del ensayo, y que es una muy clara toma de posición a favor de las emociones humanamente bondadosas, se explicita desde el principio del texto y nos invita a reflexionar que si bien toda agrupación humana que presente las características de un colectivo que persigue determinados intereses está movida por lo emocional y lo corporal, lo destacable en los movimientos que Álvaro expone en Cuando azota el frío, es que sus expresiones de emotividad y corporalidad comunitaria son humanamente bondadosas o, lo que es lo mismo, en palabras un tanto frommianas, son apuestas por la vida y el bien común.

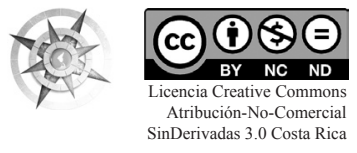

Esperanza: los afectos y el cuerpo como fundamentos de la vida en 139 Cuando azota el frío (EUNA, 2017), de Álvaro Vega Sánchez Gilbert Ulloa Brenes 
Por otro lado, y en consonancia con lo anterior, la mirada sociológica desde donde Álvaro ve para escribir permite ir más allá de los clásicos esquemas de trabajos como los de Freud (y en parte del mismo Fromm, por ejemplo en su análisis del nacionalsocialismo como fenómeno social), en los cuales fenómenos organizacionales y colectivos eran comprendidos desde una doble identificación: la del individuo con los otros, y aquella que se centraba en la figura de un líder o caudillo en quien se encarna simbólicamente lo paterno.

En el caso de los movimientos en torno a los cuales se urden las tesis de Álvaro, se revela ciertamente una nueva forma de constitución de comunidades afectivas, en las que la presencia de un líder deja de tener relevancia, y cobra mayor protagonismo la dinámica intersubjetiva de la identificación fraternal. Aún más, podríamos decir sin reparo que la figura de cualquier tipo de líder y el liderazgo como tal dentro de esos movimientos, pierde toda su funcionabilidad como elemento cohesionador, quedando de ese modo en primer lugar la construcción fraternal de los afectos como el principal (y acaso único) elemento de comunión entre los individuos.

Esa idea que está efectivamente presente en Cuando azota el frío, ofrece nuevas herramientas para la interpretación de los movimientos sociales contemporáneos e impele a la revisión de esos clásicos esquemas que subsisten de forma más o menos explícita en ciertas aproximaciones de algunos científicos sociales (cuyo más drástico ejemplo son los análisis politológicos que hoy abundan en los noticieros nacionales, donde sigue mirándose la realidad de los partidos políticos desde el vetusto esquema de las relaciones entre el líder-candidato y los votantes o la añoranza de algunos sectores por la venida de un nuevo líder que mesiánicamente saque al país del foso en el que pretendidamente se hunde).

Asimismo, en su referencia a la corporalidad Álvaro tiene el virtuoso cuidado de resaltar cómo se puede apelar a una corporalidad sensible capaz de contestar a la cultura de la muerte en que cae buena parte de la visión de mundo del capitalismo: evidencia de esto último es esa morbosa atracción de ciertas expresiones de las industrias culturales, sobre todo en el cine y la televisión, por los casos de extravagantes crímenes, por las biografías de asesinos en serie, las maniobras de grandes capos de la droga o las vivencias cotidianas de equipos detectivescos dedicados al esclarecimiento de los más intrincados casos de homicidio, entre otros que se pueden citar como atisbos de una posible tensión amorosa por la muerte.

140 Esperanza: los afectos y el cuerpo como fundamentos de la vida en Cuando azota el frío (EUNA, 2017), de Álvaro Vega Sánchez Gilbert Ulloa Brenes
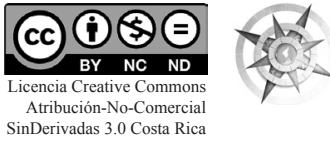
Debe observarse que también a la base de esa mediática necrofilia subyace una forma de corporalidad cuya apetencia por lo inorgánico, por lo moribundo, debe ser contrastada con las potencias de la corporalidad biofílica que Álvaro define como núcleo de las nuevas formas de resistencia organizada.

Es decir, esa dual potencialidad de lo corporal, de las energías humanas cuya sede es el cuerpo, es un aspecto alrededor del cual Álvaro no se muestra como un analista indiferente, u objetivo, como gustan decir algunos científicos, sino que en Cuando azota el frío hay un posicionamiento en favor de una corporalidad sensible basada en la bondad como medio para la resistencia colectiva que construya, paulatinamente, una globalización diferente, frente a esa cultura necrófila que caracterizaría buena parte del capitalismo contemporáneo.

Para dar cierre a esta reseña, conviene tomar en consideración lo que plantea Álvaro en el siguiente pasaje:

Lo más relevante, de acuerdo con lo que hemos venido desarrollando, es la dimensión afectiva y la incidencia que está teniendo en la redefinición del espacio público, como elemento estructurante de las relaciones de poder. Las plazas se llenan de gentes que se abrazan, danzan y comparten lo que tienen en espíritu festivo y amigable. Los mensajes en las redes sociales se revisten de gran fuerza simbólica por su desbordante e ingeniosa creatividad. El movimiento se cohesiona como fuerza social, precisamente, por ese despliegue de sentimientos, palabras y gestos que, ante todo, apelan a la afectividad, para sensibilizar sobre los derechos ciudadanos. Predominan las expresiones y los gestos de nobleza y benevolencia pacífica, que rondan las fronteras de una mística y una espiritualidad laica (Vega, 2017, p. 84).

Así, Álvaro nos invita a que cuando azota el frío de la indiferencia, de la desesperanza, de la desintegración de nuestras potencialidades y la anulación de nuestra capacidad de actuar, volvamos al abrazo, al baile, a la alegría, al gesto transformador que se puede construir desde la bondad común, como forma de humanísima y rebelada revelación.

\section{Referencias}

Fromm, E. (1953). Ética y Psicoanálisis. Bogotá: Fondo de Cultura Económica.

Fromm, E. (1970). La revolución de la esperanza. México: Fondo de Cultura Económica.

Vega, Á. (2017). Cuando azota el frío. Globalización y afectividad. Heredia: EUNA. 